\title{
Decreased sex ratio following maternal exposure to polychlorinated biphenyls from contaminated Great Lakes sport-caught fish: a retrospective cohort study. Marc G Weisskopf*1,2, Henry A Anderson ${ }^{1}$, Lawrence P Hanrahan ${ }^{1}$ and the
Great Lakes Consortium
}

Address: ${ }^{1}$ Bureau of Environmental Health, Wisconsin Department of Health and Family Services, Madison, WI, USA and ${ }^{2}$ Current address: Harvard School of Public Health, Dept. of Environmental Health, Occupational Health Program, 665 Huntington Ave Boston MA 02115, USA

Email: Marc G Weisskopf* - mweissko@hsph.harvard.edu; Henry A Anderson - anderha@dhfs.state.wi.us;

Lawrence P Hanrahan - hanralp@dhfs.state.wi.us; the Great Lakes Consortium -

* Corresponding author

Published: 12 March 2003

Environmental Health: A Global Access Science Source 2003, 2:2

This article is available from: http://www.ehjournal.net/content/2/I/2

(c) 2003 Weisskopf et al; licensee BioMed Central Ltd. This is an Open Access article: verbatim copying and redistribution of this article are permitted in all media for any purpose, provided this notice is preserved along with the article's original URL.
Received: 30 December 2002

Accepted: 12 March 2003

\begin{abstract}
Background: Fish from the Great Lakes are contaminated with polychlorinated biphenyls, which have been found to have several adverse reproductive effects. Several environmental contaminants have been found to alter the sex ratio of offspring at birth, but the evidence of such an effect of polychlorinated biphenyls has been inconsistent.

Methods: We examined parental serum polychlorinated biphenyl concentration in relation to the sex ratio of 173 children of mothers and 208 children of fathers from the Great Lakes region of the United States between 1970 and 1995. We calculated odds ratios for a male child using logistic regression and generalized estimating equations with adjustment for the year of birth of the child, maternal and paternal age, the mother's parity at the child's birth, and whether the child had an older brother.

Results: The adjusted odds ratio for having a male child among mothers in the highest quintile of serum polychlorinated biphenyl concentration was 0.18 (95\% Cl: $0.06-0.59)$ compared to mothers in the lowest quintile. Treating exposure as a continuous variable, the adjusted odds ratio for having a male child was 0.54 per unit increase in the natural log of maternal serum polychlorinated biphenyl concentration (95\% Cl: 0.33-0.89). There was little evidence of an association with paternal exposure. We found no association between either maternal or paternal serum dichlorodiphenyldichloroethene concentration and the sex ratio.
\end{abstract}

Conclusions: These findings suggest that maternal exposure to polychlorinated biphenyls may decrease the sex ratio of offspring. These data add to the growing body of evidence that exposure to particular chemicals can alter the sex ratio at birth.

\section{Background}

Contamination of the Great Lakes has led to the bioaccumulation of polychlorinated biphenyls (PCBs) in fish, particularly the larger predator species prized by sport- fishers [1-3]. These compounds are synthetic organochlorines (OC) that, along with dichlorodiphenyl-dichloroethene (DDE), comprise the bulk of OC residues found in human tissues [4], and some of the highest body 
burdens of PCBs in humans are found among fish consumers [5-8]. Consumption of these contaminated Great Lakes fish has been associated with several adverse reproductive outcomes including shortened menstrual cycle [9], reduced fecundability $[10,11]$, reduced neonatal size [12], and neurologic disorders [13-15].

For much of the $20^{\text {th }}$ century the secondary sex ratio (male births/all births) has been declining in many countries [16-18]. It has been speculated that this declining sex ratio is a sentinel indicator of environmental contamination [17], although others have argued that, on a population level, this is not the case $[16,18-21]$. There is evidence, however, that hormonal levels around the time of conception are associated with the sex ratio of offspring [22], and there is compelling evidence that exposure to particular chemicals does lead to changes in the sex ratio of offspring [23-27], as seen, for example, with exposure to dioxins following an explosion at an herbicide plant in Seveso, Italy $[26,27]$. Animal studies have suggested that exposure to PCBs may lower the sex ratio of offspring [28-30]. Studies among human populations exposed to PCBs in different settings, however, have suggested increases [31], decreases $[32,33]$, or no change $[34,35]$ in the sex ratio. To examine whether increased parental serum PCB concentration is associated with changes in the sex ratio we looked at both maternal and paternal serum PCB levels in a cohort from the Great Lakes region of the United States.

\section{Methods}

\section{Study sample}

Under the Congressional Great Lakes Critical Programs Act of 1990, the health departments of Wisconsin, Illinois, Indiana, Ohio, and Michigan formed a consortium to assess PCB and DDE exposure risks and reproductive effects of contaminated Great Lakes Sport-Caught Fish (GLSCF) consumption. This study is part of the work of that consortium and the methods are described in detail elsewhere [8,36]. In brief, between 1993-1995 we interviewed by telephone charter boat captains from consortium states who were active in 1992 and their spouses (presumed frequent GLSCF consumers: captains cohort, $\mathrm{n}$ $=1863$ households; approximately $83 \%$ response rate). In order to include more persons with low GLSCF consumption, we used random digit dialing with matching to the captains cohort by age and region (first six digits of the telephone exchange) to contact the general population. Only those contacted persons who had eaten no GLSCF in the year before the survey and not more than five meals in any year since 1970 were eligible (infrequent consumers cohort, $\mathrm{n}=1274$ households; approximately $65 \%$ response rate). Participants in the upper quartile of GLSCF consumption were later re-contacted and asked to donate blood as were controls matched by geographic region and age to the high GLSCF consumers (approximately 48\% and 30\% response rates, respectively). Two-hundred and sixty-two women and 363 men donated blood, which was analyzed from 1994 through 1995. Two-hundred and forty-two of the women who donated blood had children and 153 of the men had children. We searched for birth certificates of self-reported children. If either the birth certificate or the mother indicated that a child was not a singleton birth, that child was excluded from analysis.

\section{$P C B$ and DDE analysis}

Subjects abstained from eating sport fish for 72 hours before donating blood, and fasted completely from dinner the night before until the blood draw the next morning. Thirty milliliters of blood was collected from each donor. The whole blood was collected in red-top vacutainer tubes (no anticoagulant or serum separator). It was allowed to clot for at least 20 minutes, then centrifuged for 15 minutes at $2500 \mathrm{rpm}$. The serum was transferred with solventrinsed glass vials. The analyte was subsequently stored at $20^{\circ} \mathrm{C}$ until laboratory testing. Five milliliters of serum was analyzed for DDE and several PCB congeners using the capillary column gas chromatography with the electron capture method [37]. Copies of the PCB and DDE laboratory methods and quality control protocols are available from the authors upon request.

Blood analyses were performed by two laboratories: the Wisconsin State Laboratory of Hygiene, Madison, WI, and the Michigan Department of Community Health Laboratory, Lansing, MI. Prior to laboratory analysis, both laboratories participated in a quality assurance/laboratory standardization protocol. Each laboratory had to process two standards, of both high- and low-level concentration. Analysis of the subject's samples did not begin until the results of both standards were comparable between both laboratories. Duplicates and spiked samples were routinely run with each batch of approximately 10 samples to ensure precision and accuracy were maintained. For samples run in duplicate, the average percent difference was $20 \%$ or less for individual PCB congeners. Recoveries of spiked samples were greater than $90 \%$ for the individual congeners. Percent recovery and precision among duplicates was equally good for DDE.

Limits of detection were determined statistically for each congener [38] and any instrument response below the limit of detection was reported as a nondetect. The limits of detection for the individual PCB congeners assessed and the percentage of nondetects for samples analyzed at both the Wisconsin State Laboratory of Hygiene and the Michigan Department of Community Health Laboratory are shown in tables 1 and 2, respectively. Several methods have been proposed to assign values to samples that are below the limit of detection, all of which may introduce bias [39-41]. We have used a method based on one 
Table I: Limit of detection (LOD) and percentage of nondetects (ND) for 350 samples analyzed at the Wisconsin State Laboratory of Hygiene.

\begin{tabular}{|c|c|c|c|c|c|c|c|c|}
\hline $\begin{array}{l}\text { PCB congener } \\
\text { (IUPAC*) }\end{array}$ & LOD (ng/mL) & $\%$ ND & $\begin{array}{l}\text { PCB congener } \\
\text { (IUPAC) }\end{array}$ & LOD (ng/mL) & $\%$ ND & $\begin{array}{l}\text { PCB congener } \\
\text { (IUPAC) }\end{array}$ & LOD (ng/mL) & $\%$ ND \\
\hline$\# 5 / 8$ & 1.20 & 100 & $\# 56 / 60$ & 0.35 & 100 & $\#|4|$ & 0.15 & 100 \\
\hline \#6 & 0.65 & 100 & $\# 66 / 95$ & 0.55 & 98.9 & \#146 & 0.20 & 80.3 \\
\hline$\# 7 / 9$ & 0.40 & 100 & \#70/76 & 0.25 & 100 & \#|5| & 0.15 & 100 \\
\hline \#15/17 & 060 & 100 & \#74 & 0.25 & 80.6 & $\# 167$ & 0.25 & 99.4 \\
\hline \#16/32 & 0.55 & 100 & $\# 77 / 110$ & 0.25 & 100 & \#170/190 & 0.35 & 80.9 \\
\hline$\# 18$ & 0.35 & 100 & $\# 82$ & 0.20 & 100 & \#17I/202 & 0.15 & 96.0 \\
\hline$\# 19$ & 0.40 & 100 & \#84/92 & 0.55 & 100 & \#172/197 & 0.30 & 95.7 \\
\hline \#22 & 0.50 & 100 & $\# 85^{\dagger}$ & 0.25 & 100 & \#174 & 0.20 & 100 \\
\hline$\# 24 / 27$ & 0.30 & 100 & $\# 87$ & 0.20 & 100 & \#177 & 0.20 & 93.4 \\
\hline \#26 & 0.25 & 100 & \#91 & 0.25 & 100 & $\# 178$ & 0.35 & 96.6 \\
\hline$\# 28 / 31$ & 0.60 & 100 & \#97 & 0.15 & 100 & $\# 180$ & 0.20 & 9.7 \\
\hline \#33 & 0.25 & 100 & \#99 & 0.25 & 84.3 & \#182/187 & 0.10 & 39.3 \\
\hline$\# 37 / 42$ & 0.30 & 100 & $\#|0|$ & 0.30 & 100 & $\# 183$ & 0.15 & 86.3 \\
\hline$\# 40$ & 0.30 & 100 & $\# 105 / 132 / 153$ & 0.20 & 7.1 & \#185 & 0.15 & 100 \\
\hline$\# 4|/ 7| / 64$ & 0.40 & 100 & \#118 & 0.20 & 57.3 & \#194 & 0.15 & 74.9 \\
\hline$\# 44$ & 0.30 & 100 & $\# 123 / 149$ & 0.15 & 100 & \#195/208 & 0.10 & 92.3 \\
\hline$\# 45$ & 0.30 & 100 & $\# 128$ & 0.25 & 100 & \#196/203 & 0.30 & 70.7 \\
\hline$\# 46$ & 0.40 & 100 & \#135/144 & 0.30 & 100 & \#199 & 0.15 & 99.7 \\
\hline$\# 47 / 48$ & 0.40 & 100 & $\# 136{ }^{\dagger}$ & 0.30 & 100 & $\# 201$ & 0.20 & 56.7 \\
\hline$\# 49$ & 0.25 & 100 & \#137/176 & 0.10 & 100 & \#206 & 0.15 & 91.5 \\
\hline \#52 & 0.25 & 100 & \#138/163 & 0.25 & 10.8 & & & \\
\hline
\end{tabular}

* International Union of Pure and Applied Chemistry $†$ Interference from contamination prevented determination of concentrations of these congeners in all but I sample. The one remaining sample was nondetectable for both congeners.

described by Hornung and Reed [40] and modified in conjunction with scientists from the Centers for Disease Control and Prevention to reduce overestimation when summing many individual congeners for which few of the samples are detectable. Specifically, if at least $50 \%$ of the samples had detectable values for the analyte (PCB congener), the concentration for any nondetect was imputed by dividing the limit of detection by the square root of two. If less than $50 \%$ of the samples had detectable values, the concentration for any nondetect was left at 0 . This imputation was done separately for samples analyzed at the Wisconsin State Laboratory of Hygiene and samples analyzed at the Michigan Department of Public Health Laboratory. Congener-specific $\mathrm{PCB}$ values were summed to yield a PCB total for each subject. In our sample, this imputation procedure resulted in total PCB concentrations that were only marginally greater than those obtained if all nondetects were assigned 0 . The mean PCB concentrations by exposure category are shown in table 3 for both the sum using imputed values for nondetects and the sum with nondetects assigned 0 . The limit of detection for DDE in the Wisconsin State Laboratory of Hygiene was $0.25 \mathrm{ng} / \mathrm{mL}$. Only 1 of 350 samples was below this limit, and it was assigned a value of 0.125 . The limit of detection for DDE in the Michigan Department of Public Health Laboratory was $0.50 \mathrm{ng} / \mathrm{mL}$. Only 13 of 275 samples were below this limit, and they were assigned a value of 0.25 .

\section{Data analysis}

The sex ratio we report is defined as the number of male births divided by the total number of live births (often referred to as the secondary sex ratio). The sex of fetuses that do not result in a live birth are not considered. Worldwide, this sex ratio is fairly constant at 0.514 [22] and this is exactly what it is for the children of white women in Wisconsin between 1970 and 1995 (Wisconsin Bureau of Health Information natality data). Because of the uncertainty in changes in maternal serum PCB concentration as a result of childbirth and breastfeeding practices [42], we only considered the sex of the last (at the time of the blood donation) child of each mother. This also was, therefore, the birth closest in time to the blood analysis. Because the birth of a child should not alter paternal serum PCB concentration, we considered the sex of all children of each father in our sample to increase the power of our analysis.

We had complete data for a total of 173 mothers and 108 fathers who donated blood for analysis. In one analysis both maternal and paternal PCB levels were included in the same model, and therefore only the last child of couples for whom we had blood samples from both parents were included $(n=76)$. Otherwise, separate analyses were run for maternal and paternal exposure, and the 76 children for whom we had blood samples from both parents were included in both maternal and paternal analyses. 
Table 2: Limit of detection (LOD) and percentage of nondetects (ND) for 275 samples analyzed at the Michigan Department of Community Health Laboratory.

\begin{tabular}{|c|c|c|c|c|c|c|c|c|}
\hline $\begin{array}{l}\text { PCB congener } \\
\text { (IUPAC) }\end{array}$ & LOD (ng/mL) & $\%$ ND & $\begin{array}{l}\text { PCB congener } \\
\text { (IUPAC) }\end{array}$ & LOD (ng/mL) & $\%$ ND & $\begin{array}{l}\text { PCB congener } \\
\text { (IUPAC) }\end{array}$ & LOD (ng/mL) & $\%$ ND \\
\hline$\# 5$ & 0.30 & 100 & \#76 & 0.10 & 100 & $\# 158$ & 0.10 & 95.3 \\
\hline$\# 6$ & 0.50 & 100 & $\# 77$ & 0.10 & 100 & $\# 170 / 190$ & 0.10 & 16.3 \\
\hline$\# 7 / 9$ & 0.80 & 100 & \#82 & 0.10 & 100 & \#17| & 0.05 & 80.1 \\
\hline$\# 8$ & 0.80 & 100 & \#84 & 0.10 & 96.4 & \#172 & 0.10 & 75.4 \\
\hline$\# 15$ & 0.30 & 100 & \#85 & 0.05 & 99.3 & \#174 & 0.10 & 99.3 \\
\hline$\# 16$ & 0.10 & 99.6 & \#87 & 0.10 & 93.5 & \#175 & 0.15 & 100 \\
\hline \#22 & 0.50 & 100 & \#91 & 0.20 & 99.3 & \#176 & 0.20 & 100 \\
\hline$\# 25$ & 0.20 & 100 & \#92 & 0.60 & 99.6 & \#177 & 0.20 & 87.3 \\
\hline$\# 26$ & 0.20 & 100 & \#97 & 0.10 & 98.6 & $\# 178$ & 0.20 & 86.2 \\
\hline \#28 & 0.70 & 100 & \#99 & 0.10 & 33.7 & \#179 & 0.10 & 100 \\
\hline \#31 & 0.70 & 100 & $\# 100$ & 0.10 & 100 & $\# 180$ & 0.10 & 4.7 \\
\hline \#33 & 0.60 & 100 & $\# 101$ & 0.15 & 91.7 & $\# 182$ & 0.30 & 100 \\
\hline \#37/42 & 0.20 & 100 & $\# 105$ & 0.10 & 54.7 & $\# 183$ & 0.10 & 60.5 \\
\hline$\# 40$ & 0.10 & 100 & \#110 & 0.10 & 82.2 & $\# 185$ & 0.10 & 100 \\
\hline \#4|/7I & 0.20 & 100 & \#118 & 0.10 & 21.4 & \#187 & 0.05 & 18.8 \\
\hline$\# 44$ & 0.40 & 100 & $\# 123$ & 0.05 & 100 & $\# 193$ & 0.20 & 94.6 \\
\hline$\# 45$ & 0.20 & 99.6 & $\# 128$ & 0.10 & 97.8 & $\# 194$ & 0.03 & 14.1 \\
\hline$\# 46$ & 0.10 & 99.6 & $\# 132$ & 0.10 & 98.9 & $\# 195$ & 0.03 & 58.3 \\
\hline$\# 47$ & 0.10 & 100 & $\# 135$ & 0.40 & 100 & \#196/203 & 0.25 & 69.6 \\
\hline$\# 48$ & 0.20 & 100 & $\# 136$ & 0.15 & 99.3 & \#198 & 0.30 & 100 \\
\hline$\# 49$ & 0.20 & 100 & \#137 & 0.05 & 100 & $\# 199$ & 0.06 & 100 \\
\hline \#52 & 1.30 & 100 & \#138/163 & 0.15 & 2.9 & $\# 200$ & 0.30 & 100 \\
\hline$\# 56$ & 0.10 & 98.9 & $\# 141$ & 0.10 & 99.6 & \#201 & 0.20 & 46.0 \\
\hline$\# 60$ & 0.30 & 100 & \#144 & 0.10 & 99.6 & \#202 & 0.03 & 92.4 \\
\hline \#63 & 0.10 & 100 & \#146 & 0.15 & 55.8 & \#205 & 0.20 & 100 \\
\hline$\# 64$ & 0.10 & 100 & $\# 149$ & 0.30 & 99.3 & \#206 & 0.03 & 68.1 \\
\hline$\# 66 / 95$ & 0.50 & 94.6 & $\#|5|$ & 0.10 & 97.5 & \#207 & 0.35 & 100 \\
\hline \#70 & 0.30 & 99.3 & $\# 153$ & 0.10 & 2.9 & \#208 & 0.03 & 91.3 \\
\hline \#74 & 0.10 & 100 & \#157 & 0.25 & 100 & & & \\
\hline
\end{tabular}

* International Union of Pure and Applied Chemistry

The parity of the mother (the number of live births) was treated as a categorical variable $(1,2$, or $>2)$ and dummy variables for parity 2 and $>2$ were included as potential confounders. If we could identify a mother's first child from a blank entry under "last live birth" on the birth certificate, then we could determine the mother's parity at the birth of each of her children directly by counting subsequent children. If we could not determine a mother's parity in this manner, but we could identify for a given child at least 1 (non-firstborn) child of the same mother born earlier, then the mother's parity at the later child would have to be at least 3 and therefore was coded as $>2$. There is not much data on the reliability of the "last live birth" entry on the birth certificate, but 2 U.S. reports have found birth certificate data on birth order to be extremely good, with concordance rates with medical records of greater than $97 \%[43,44]$. In addition, in our data every child who we knew from the mother was not a first child did have an entry under "last live birth" on their birth certificate. Age of the parents at a given birth was determined from the questionnaire. Self-reported years of GLSCF consumption and childrens' birth dates were used to determine whether a parent had eaten GLSCF prior to the pregnancy. Because GLSCF consumption contributes greatly to OC exposure, if a parent had eaten GLSCF, but not before the pregnancy of a given child being analyzed, for that child we assigned the parent the median PCB and DDE concentrations of the infrequent consumers.

We performed our analyses on all subjects with complete data. We were missing data on the last child of 69 mothers and 61 children of 45 fathers with blood samples - primarily data on maternal parity, which was missing for the last child of 68 mothers and 57 children of 43 fathers. Considering only the last child of each mother, the sex ratio was lower among the children of the mothers who were missing data (0.493) than among the children of mothers who were not missing data (0.572). The PCB concentrations among the 69 mothers who were missing data were higher (geometric mean: $2.07 \mathrm{ng} / \mathrm{mL}$ ) than for the mothers who were not missing data (geometric mean: $1.56 \mathrm{ng} / \mathrm{mL}$ ). Therefore, by excluding mothers with missing data, we would potentially bias against finding a decreasing sex ratio with increasing PCB levels. The same pattern held for fathers: for fathers who were missing data, the sex ratio among their children was lower (0.426) and the fathers' 
Table 3: Characteristics of mothers and their children by maternal serum PCB quintile.

\begin{tabular}{|c|c|c|c|c|c|}
\hline & \multicolumn{5}{|c|}{ Quintile of serum PCB } \\
\hline & I & 2 & 3 & 4 & 5 \\
\hline Mothers, n & 34 & 35 & 35 & 35 & 34 \\
\hline Children analyzed, $\mathrm{n}$ & 34 & 35 & 35 & 35 & 34 \\
\hline $\begin{array}{l}\text { Serum PCB (ng/mL)- nondetects imputed, geometric mean } \\
\text { (range) }\end{array}$ & $0.7(0.5-0.9)$ & $1.0(0.9-1.1)$ & $1.4(1.1-1.7)$ & $2.2(1.7-3.0)$ & $4.7(3.0-12.1)$ \\
\hline $\begin{array}{l}\text { Serum PCB }(\mathrm{ng} / \mathrm{mL}) \text { - nondetects assigned } 0 \text {, geometric mean } \\
\text { (range) }\end{array}$ & $0.5(0-0.8)$ & $0.8(0.4-1.1)$ & I.I (0.7-I.6) & $2.1(1.4-2.9)$ & $4.6(2.9-11.9)$ \\
\hline Crude sex ratio & 0.706 & 0.629 & 0.457 & 0.657 & 0.412 \\
\hline Year of child's birth, mean $\pm s d$ & $1988 \pm 5$ & $1983 \pm 7$ & $1985 \pm 7$ & $1982 \pm 6$ & $1980 \pm 6$ \\
\hline Yrs between delivery and blood analysis, mean \pm sd & $6.2 \pm 5.1$ & $10.1 \pm 6.8$ & $8.9 \pm 6.8$ & $\mid \mathrm{I} . \mathrm{I} \pm 6 . \mathrm{I}$ & $13.6 \pm 5.8$ \\
\hline Father's age (yrs) at delivery, mean \pm sd & $31.2 \pm 5.5$ & $31.3 \pm 5.0$ & $33.9 \pm 5.5$ & $32.3 \pm 6.9$ & $30.6 \pm 5.3$ \\
\hline Mother's age (yrs) at delivery, mean \pm sd & $29.7 \pm 4.9$ & $29.2 \pm 3.8$ & $30.3 \pm 4.9$ & $29.4 \pm 4.0$ & $28.3 \pm 4.6$ \\
\hline Captains cohort, n (\%) & $16(47.1)$ & $30(85.7)$ & $29(82.9)$ & $34(97.1)$ & $33(97.1)$ \\
\hline Previous male child, $\mathrm{n}(\%)$ & $19(55.9)$ & $26(74.3)$ & $19(54.3)$ & $16(45.7)$ & $17(50.0)$ \\
\hline \multicolumn{6}{|l|}{ Parity of mother, n (\%) } \\
\hline 1 & $7(20.6)$ & $13(37.1)$ & $12(34.3)$ & 9 (25.7) & $7(20.6)$ \\
\hline 2 & $17(50.0)$ & $15(42.9)$ & $16(45.7)$ & $21(60.0)$ & $19(55.9)$ \\
\hline$>2$ & $10(29.4)$ & $7(20.0)$ & $7(20.0)$ & $5(14.3)$ & $8(23.5)$ \\
\hline
\end{tabular}

PCB concentrations higher (geometric mean: $2.85 \mathrm{ng} / \mathrm{mL}$ ) than for fathers without missing data (ratio: 0.510; geometric mean PCB: $2.76 \mathrm{ng} / \mathrm{mL}$ ). Therefore excluding fathers with missing data would also potentially bias against finding a decreasing sex ratio with increasing PCB levels.

Because the blood draws were carried out a varying number of years after the births analyzed, we ran additional analyses after using a toxicokinetic model to revise serum OC measurements to account for decay over time. Making the assumptions that subjects have achieved an equilibrium between their OC intake and excretion, that they reach a new OC equilibrium faster than OC concentrations in fish are changing, and that the subjects' fish consumption is stable over time, then the decay of the body burden of OCs should be governed by the decrease in OC concentration in fish over time. Since PCB contamination of fish in the Great Lakes has been found to be declining in a manner well described by first order kinetics [1] we revised serum OC measurements according to the formula:

$[\mathrm{OC}]_{\text {revised }}=[\mathrm{OC}]_{\text {measured }} \times \exp (\lambda \times \mathrm{t})$

where $\lambda$ is the decay constant for OCs in the fish and $t$ is the number of years between the birth analyzed and the analysis of the subject's blood (Appendix [see additional file 1). We used fish OC decay constants of 0.06, 0.08, and 0.15 , chosen to cover a range of decay rates that describe reported decreases in OC levels of GLSCF over time [1]. $[\mathrm{OC}]_{\text {revised }}$ is then the estimated serum OC concentration at the time of the birth analyzed, and $[\mathrm{OC}]_{\text {measured }}$ is the OC concentration we measured in 1994-1995. Because this model assumes that the subjects' fish consumption is stable over time, after revising serum OC concentrations based on this model, we performed analyses both on each entire group of fathers or mothers, and then also on only those who did not report that their GLSCF consumption had changed a lot. This was determined from the responses to the following question on the questionnaire: "Since you first began eating sport-caught fish from the Great Lakes, has the amount of fish that you have eaten each year increased a lot, increased somewhat, remained about the same, decreased somewhat or decreased a lot?" Quintiles of exposure were determined for each separate regression analysis.

When PCB and DDE measurements were analyzed as a continuous variable, they were transformed to the natural log scale because they were skewed towards higher concentrations. The distribution of the natural logs of serum PCB concentrations for the mothers and the fathers included in our analysis are shown in figures $1 \mathrm{a}$ and $2 \mathrm{a}$, respectively, by the year of birth and sex of the children. Also shown (Figures $1 \mathrm{~b}$ and $2 \mathrm{~b}$ ) are the revised natural logs of the parental serum PCB concentrations after applying the toxicokinetic model with a decay constant of 0.15 - the revision that led to the most change in the natural $\log$ of the PCB concentrations. When only the last child of parents was analyzed, we calculated adjusted odds ratios (aOR) for male births and Wald 95\% CI using logistic regression. To analyze all children of fathers - which involved repeated observations from a single father - we 
used generalized estimating equations with an unstructured correlation matrix to calculate aOR and 95\% CI from empirical standard error estimates. Mean values are shown in the text and tables \pm their standard deviation (sd). SAS version 8 [45] was used for all analyses.

\section{Results}

The sex ratio among the last children of the mothers with complete data was 0.572 . This ratio was higher than the expected ratio of 0.514 because only the last child of each mother was considered. The sex ratio among all children of the mothers in our sample $(n=359)$ was 0.535 . The sex ratio among all children of fathers with complete data was 0.510 . Characteristics by exposure status of mothers and fathers and their children in our analyses are shown in tables 3 and 4, respectively. The higher than expected sex ratios among the last children of mothers in our sample, as well as a decrease in this ratio as maternal PCB exposure increases, can be seen in the crude sex ratios by exposure quintile in table 3 . We compared the sex ratio among the children born to parents in each quintile of serum PCB concentration to those in the lowest quintile, adjusting for the year of the child's birth, paternal and maternal age at the child's birth, the mother's parity, and whether the child had an older brother (Figure 3). Our results were not materially affected if we included an indicator variable in the model for whether the parent was from the captain's cohort or one of the infrequent GLSCF consumers.

Compared to mothers in the lowest quintile of serum PCB concentration, the odds of a male child for mothers in higher quintiles steadily decreased (Figure 3a). The odds of a male child among mothers in the highest PCB quintile compared to the lowest was reduced by $82 \%$ (OR: 0.18 ; 95\% CI: 0.06-0.59). When maternal serum PCB concentration was treated as a continuous linear variable, the odds of a male child decreased by $46 \%$ for every unit increase in the natural log of serum PCB concentration (OR: 0.54 ; 95\% CI: $0.33-0.89$ ). We saw no effect of paternal serum PCB concentration on the odds of a male child (Figure 3b). The pattern of effects of both maternal and paternal serum PCB concentrations were not materially affected by simultaneously adjusting for maternal and paternal PCB levels, although the confidence intervals became wider because there were only 76 couples for whom we had blood analyzed from both parents. There remained no association between paternal PCB exposure and odds of a male child when we restricted our analysis to the frequent GLSCF consumers only ( $n=92$ fathers, 172 children). Among the frequent GLSCF-consuming mothers $(\mathrm{n}=142)$, however, the decreasing aOR for a male child with increasing maternal PCB exposure was still seen (aOR per unit increase in the natural log of PCB concentration: 0.56 ; 95\% CI: 0.33-0.98). Similar analyses were done considering serum DDE concentrations, but we did not find consistent effects.

We ran additional analyses after applying the toxicokinetic model to revise measured serum PCB concentrations to account for the time interval between the childrens' births and the blood draw from the parents. We ran these analyses with different decay constants for PCB content in GLS$\mathrm{CF}$ over time. We first performed these analyses with either all fathers or all mothers, but because the toxicokinetic model we used assumes that a person's GLSCF consumption is stable over time, we also performed the analyses after excluding the children of those fathers ( $\mathrm{n}=$ 24) and mothers $(n=45)$ who had reported that their GLSCF consumption had changed a lot. Lastly, because the toxicokinetic model is based on changes in levels of fish contamination, it may be more appropriate for GLSCF consumers than non-consumers of GLSCF. Thus, we also ran the analyses after applying the toxicokinetic model only to those subjects who consumed GLSCF, while for subjects who were not GLSCF consumers PCB concentrations were left at the levels found at the time of the blood draw.

The relation between maternal PCB exposure and odds of a male child was robust to revision of maternal serum PCB concentrations based on the toxicokinetic model. Regardless of the decay constant, exclusion of those who reported that their GLSCF consumption changed a lot, or application of the model to GLSCF consumers only, there was always a decreasing trend in the odds ratio for a male child with increasing maternal PCB exposure. The only case in which this decreasing trend did not reach significance at a 95\% level of confidence was when mothers whose GLSCF consumption changed a lot were excluded and the model was applied to GLSCF consumers only, in which case the upper 95\% confidence limit was 1.05 (Table 5). Revision of paternal serum PCB concentration based on the toxicokinetic model led to some categories of paternal exposure having elevated odds ratios for a male birth, but this reached $95 \%$ significance in only one case, and in general the quintiles with elevated odds ratios were not the highest exposure quintiles (Table 6). Regardless of the decay constant, exclusion of those who reported that their GLSCF consumption changed a lot, or application of the model to GLSCF consumers only, there was no indication of a linear trend between odds of a male child and the natural log of paternal PCB concentration.

\section{Discussion}

Our data suggest that maternal exposure to PCBs before pregnancy, in this case primarily through consumption of contaminated fish from the Great Lakes, is associated with a decrease in the sex ratio of offspring. These results were robust to different assumptions about the decline in PCB 
A

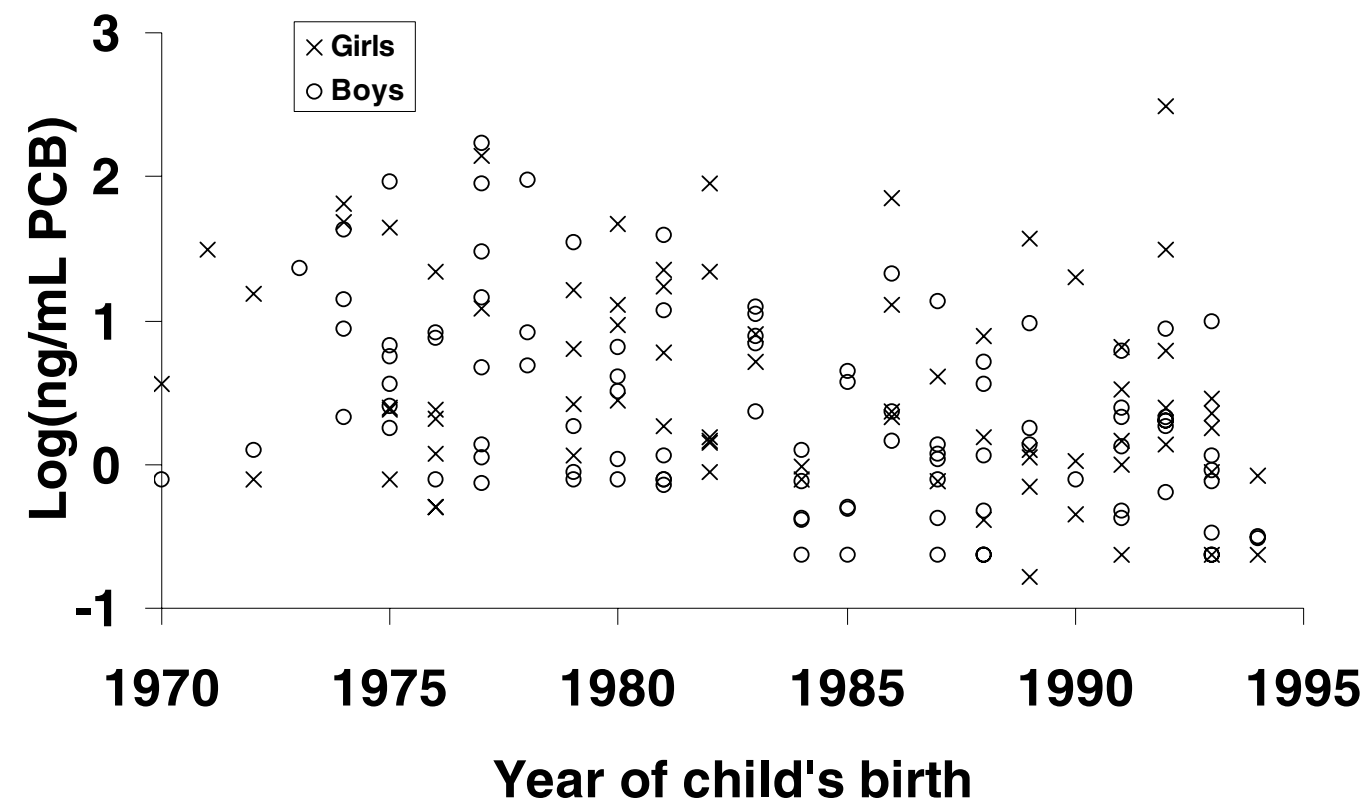

B

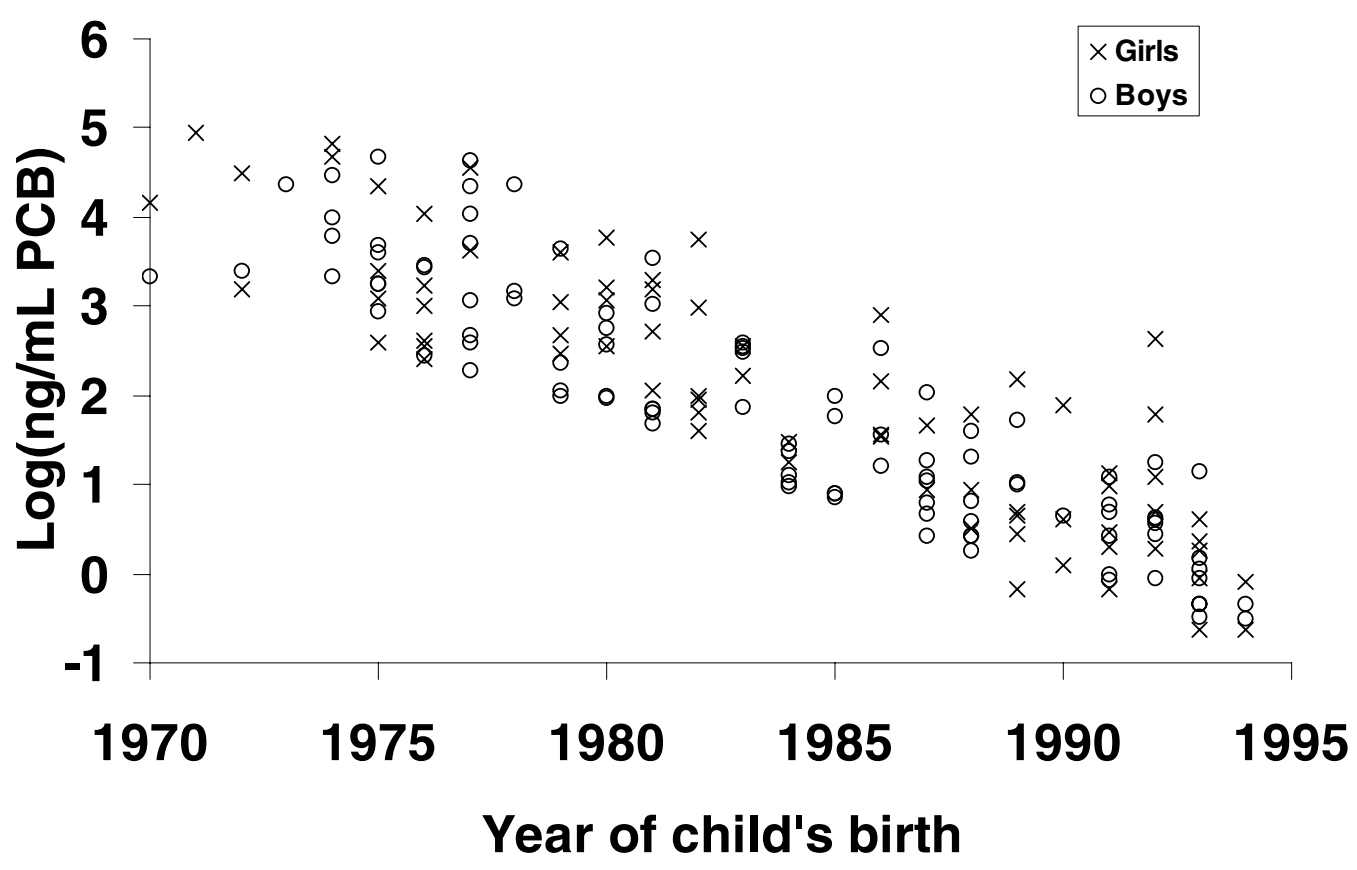

Figure I

Distribution of the natural logs of maternal serum PCB concentration $(\mathrm{ng} / \mathrm{mL})$ for each child analyzed by sex (x: girls; o: boys) and the year of the child's birth. A) Unrevised PCB concentrations as measured in 1994- 1995. B) Revised PCB concentrations according to the toxicokinetic model with a decay constant of 0.15 . 


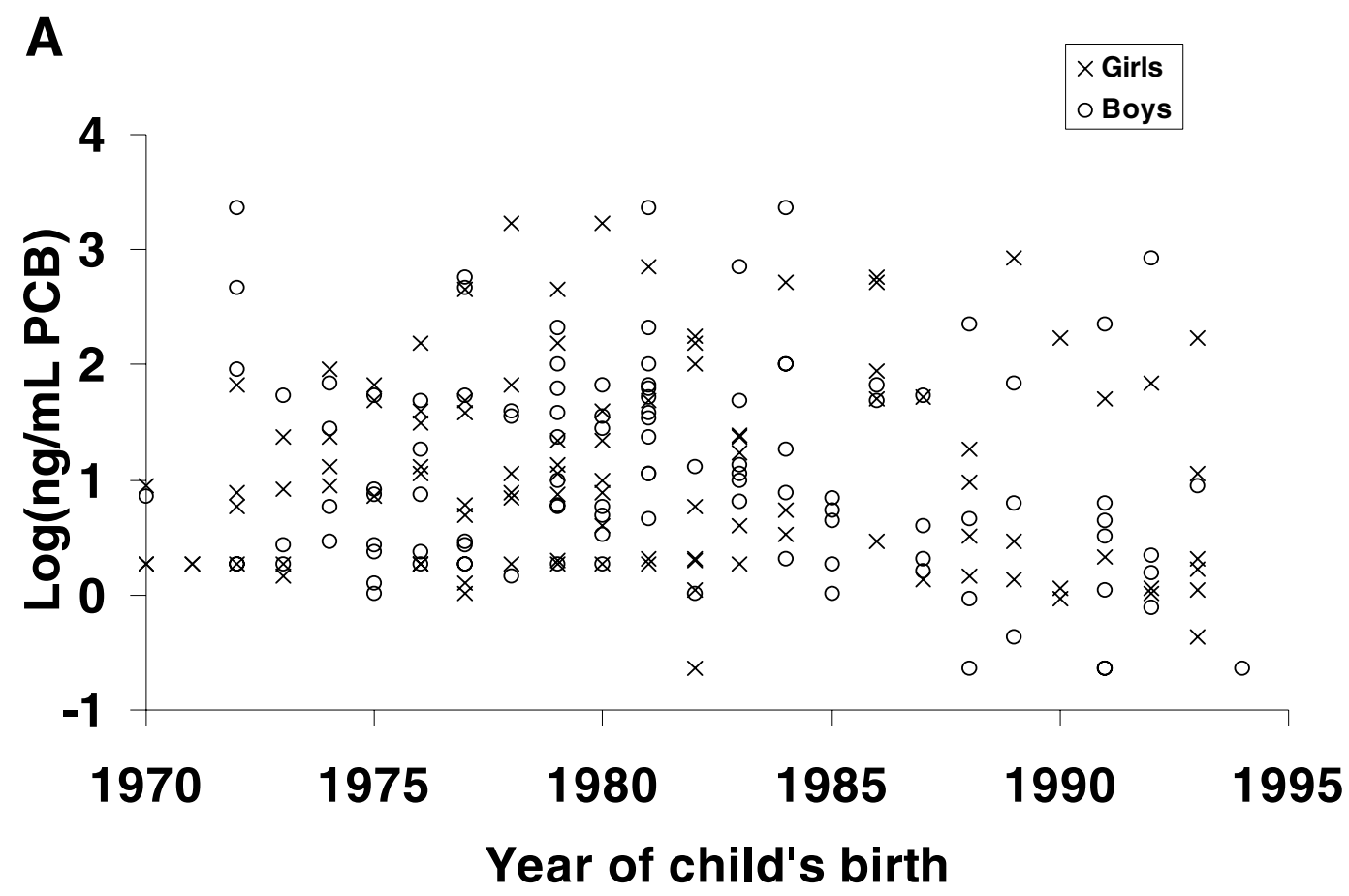

B

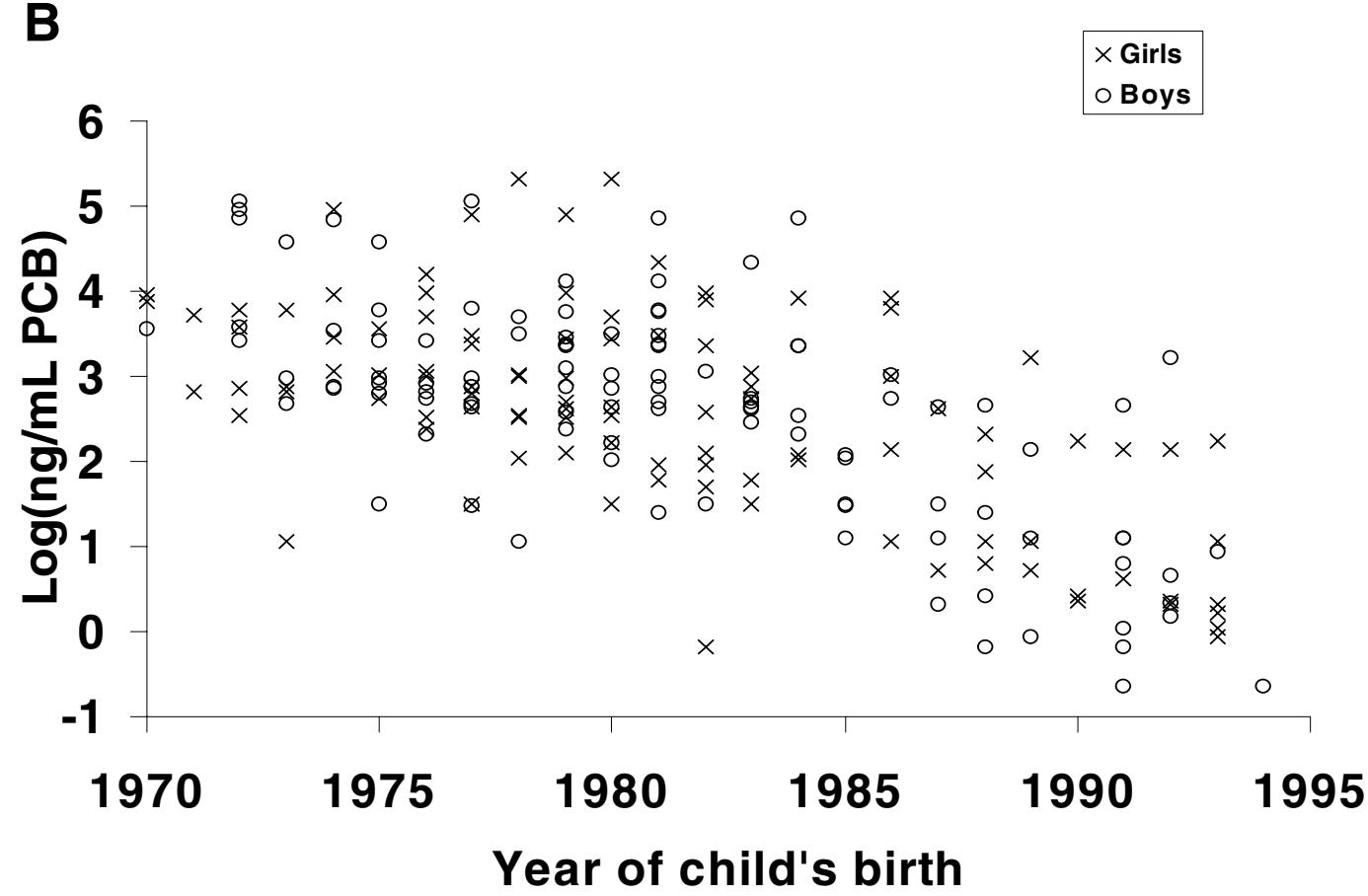

Figure 2

Distribution of the natural logs of paternal serum PCB concentration (ng/mL) for each child analyzed by sex (x: girls; o: boys) and the year of the child's birth. A) Unrevised PCB concentrations as measured in 1994-1995. B) Revised PCB concentrations according to the toxicokinetic model with a decay constant of 0.15 . 

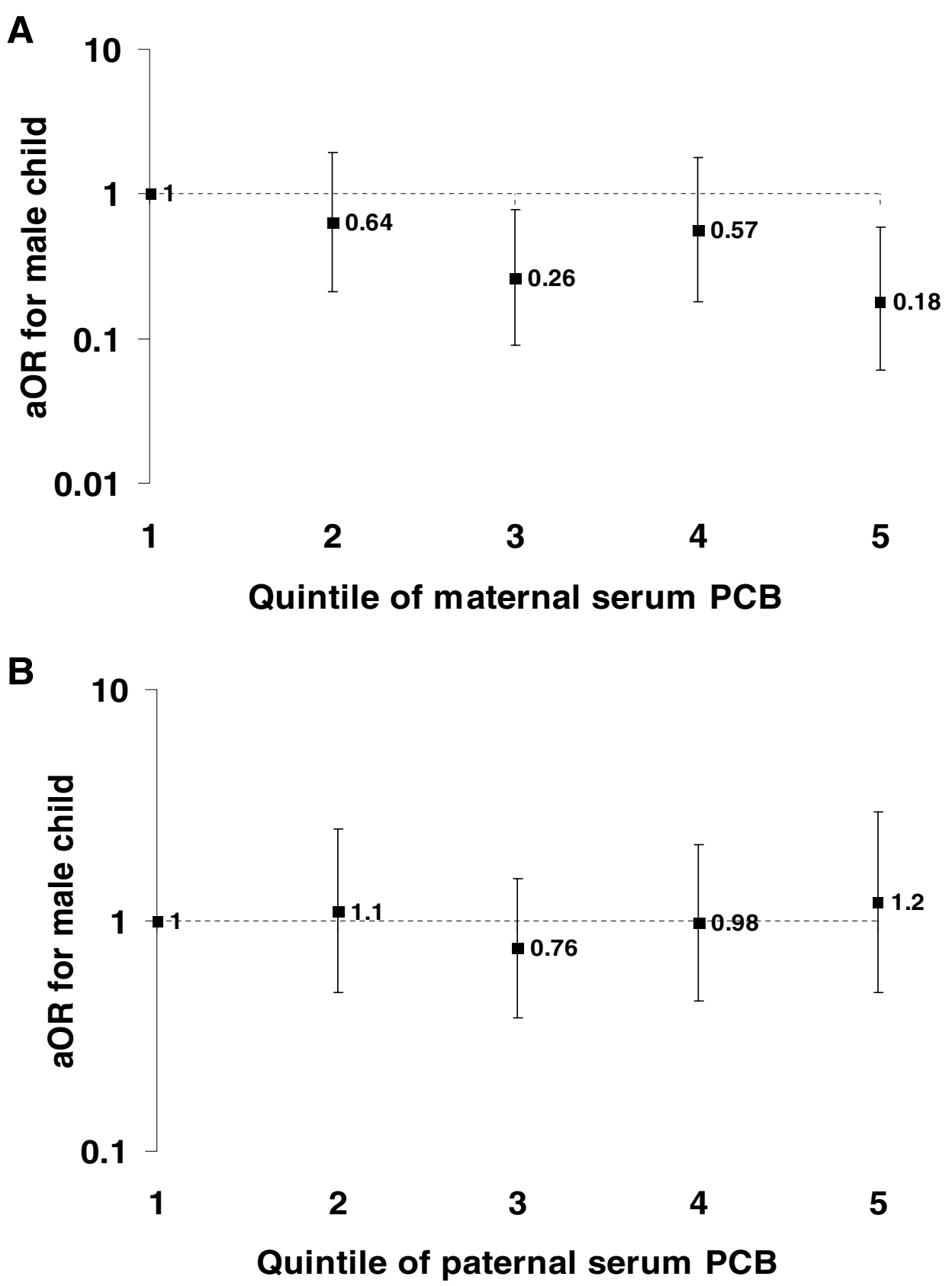

\section{Figure 3}

A) Odds ratio (squares; values indicated for each quintile) and $95 \%$ confidence intervals (vertical bars) for a male child for quintiles 2-5 of maternal serum PCB concentration with the lowest quintile as the reference group. For PCB concentration as a continuous variable, the downward trend was significant $(P=0.02)$. Adjustment was made for the year of the child's birth, maternal and paternal age at the child's birth, the mother's parity at the child's birth and whether the child had an older brother. B) Odds ratio (squares; values indicated for each quintile) and $95 \%$ confidence intervals (vertical bars) for a male child for quintiles $2-5$ of paternal serum PCB concentration with the lowest quintile as the reference group. Adjustment was made for the year of the child's birth, maternal and paternal age at the child's birth, the mother's parity at the child's birth, and whether the child had an older brother. 
Table 4: Characteristics of fathers and their children by paternal serum PCB quintile.

\begin{tabular}{|c|c|c|c|c|c|}
\hline & \multicolumn{5}{|c|}{ Quintile of serum PCB } \\
\hline & I & 2 & 3 & 4 & 5 \\
\hline Fathers, $\mathrm{n}$ & 16 & 27 & 22 & 22 & 21 \\
\hline Children analyzed, $\mathrm{n}$ & 30 & 45 & 42 & 47 & 44 \\
\hline $\begin{array}{l}\text { Serum PCB (ng/mL)- nondetects imputed, geometric mean } \\
\text { (range) }\end{array}$ & $1.0(0.5-1.3)$ & $1.4(1.3-1.8)$ & $2.4(1.9-2.9)$ & $4.4(2.9-6.1)$ & $10.7(6.2-29.1)$ \\
\hline $\begin{array}{l}\text { Serum PCB }(\mathrm{ng} / \mathrm{mL}) \text { - nondetects assigned } 0 \text {, geometric mean } \\
\text { (range) }\end{array}$ & $0.9(0-1.2)$ & $1.3(1.0-1.8)$ & $2.3(1.7-2.7)$ & $4.4(2.9-6.1)$ & $10.7(6.2-29.1)$ \\
\hline Crude sex ratio & 0.500 & 0.467 & 0.548 & 0.532 & 0.524 \\
\hline Year of child's birth, mean \pm sd & $1987 \pm 6$ & $1980 \pm 6$ & $1980 \pm 6$ & $1980 \pm 4$ & $1982 \pm 6$ \\
\hline Yrs between delivery and blood analysis, mean \pm sd & $4.9 \pm 4.9$ & $12.2 \pm 6.4$ & $11.2 \pm 5.4$ & $11.0 \pm 3.7$ & $9.6 \pm 5.1$ \\
\hline Father's age (yrs) at delivery, mean \pm sd & $31.6 \pm 4.0$ & $31.4 \pm 4.0$ & $31.6 \pm 5.6$ & $33.5 \pm 6.4$ & $35.9 \pm 7.8$ \\
\hline Mother's age (yrs) at delivery, mean \pm sd & $30.2 \pm 4.6$ & $28.7 \pm 3.3$ & $29.7 \pm 4.7$ & $30.6 \pm 4.9$ & $31.1 \pm 4.6$ \\
\hline Captains cohort, n (\%) & II (36.7) & $42(93.3)$ & $36(85.7)$ & $4 \mid(87.2)$ & $42(95.5)$ \\
\hline Previous male child, n (\%) & $9(30.0)$ & $8(17.8)$ & $7(16.7)$ & $13(27.7)$ & II (25.0) \\
\hline \multicolumn{6}{|l|}{ Parity of mother, $\mathrm{n}(\%)$} \\
\hline 1 & $16(53.3)$ & $26(57.8)$ & $20(47.6)$ & $21(44.7)$ & $21(47.7)$ \\
\hline 2 & $10(33.3)$ & $16(35.6)$ & $14(33.3)$ & $16(34.0)$ & $18(40.9)$ \\
\hline$>2$ & $4(13.3)$ & $3(6.7)$ & $8(19.1)$ & $10(21.3)$ & $5(\mathrm{I} I .4)$ \\
\hline
\end{tabular}

exposure from GLSCF over time. There was some suggestion in our data that some levels of paternal exposure to PCBs may increase the sex ratio, but these results were weak and not consistent. The mothers we excluded from analysis tended to have higher PCB levels and the sex ratio of their children was lower. Thus, the most likely direction of any resulting bias from these exclusions would have been against finding a decreasing sex ratio with increasing PCB levels, and so would be unlikely to explain our findings among mothers. Although the sex ratio among the children of the fathers we excluded from analysis was lower than among the children of those fathers in our analysis, the paternal PCB concentrations were similar. The low response rates for blood donation could also have introduced bias, the direction of which would be difficult to predict. To have contributed to the results we report for maternal exposure, those mothers who did not donate blood, compared to the mothers who did, would have had to have had either lower PCB levels and a lower sex ratio among their last children or higher РCB levels and a higher sex ratio among their children. While suspected PCB levels (possibly surmised on the basis of fish consumption) may have contributed to the choice to donate blood or not, we do not see why this would additionally have been systematically related to the sex ratio of the mothers' children.

Previous studies have found changes in sex ratio following exposure to hormonally active compounds, and different effects of chemicals on mothers and fathers could have opposing effects on the sex ratio $[22,46]$. Hormonally induced ovulation leads to a clear reduction in the sex ra- tio of offspring [47], a result that has also been found following paternal exposure to the nematocide dibromochloropropane $[23,24]$. Paternal, but not maternal, exposure to dioxin following an explosion at an herbicide factory in Seveso, Italy was found to reduce the sex ratio $[26,27]$. In contrast, among veterans of Operation Ranch Hand, the unit responsible for spraying Agent Orange and other dioxin-containing herbicides in Vietnam, paternal dioxin levels greater than $10 \mathrm{ppt}$ were associated with an increased percentage of male children [48]. In the latter study, however, maternal dioxin levels were not measured (although these would be expected not to be above background), and the paternal levels were likely somewhat lower than levels in men exposed following the Seveso incident.

The most dramatic instances of PCB exposure were the Yucheng and Yusho poisonings, when rice oil used for cooking was contaminated by heat-degraded PCBs during the manufacturing process [49-53]. Following this incident, no alteration of the sex ratio among children of exposed mothers was found $[32,34,35]$, although the sex ratio of children born to fathers younger than 20 years at the time of exposure was found to be reduced for approximately 10 years following the exposure [32].

The specific PCB congeners to which people were exposed following the Yucheng and Yusho incidents may have been somewhat different from those found in Great Lakes fish and fish consumers $[3,49,51,54-56]$, and unlike exposure to PCBs from Great Lakes fish, the Yucheng and Yusho incidents also involved significant exposure to 
Table 5: Odds ratios* $(95 \% \mathrm{Cl})$ for male child by maternal serum PCB quintile given different decay constants used to revise $\mathrm{PCB}$ concentrations.

\begin{tabular}{|c|c|c|c|}
\hline & \multicolumn{3}{|c|}{ Decay constant } \\
\hline & 0.06 & .08 & .15 \\
\hline \multicolumn{4}{|c|}{ Model applied to all mothers ( $\mathrm{n}=173$ mothers, 173 children) } \\
\hline Quintile I & 1.00 & 1.00 & 1.00 \\
\hline Quintile 2 & $0.39(0.13-1.19)$ & $0.72(0.24-2.14)$ & $0.80(0.26-2.45)$ \\
\hline Quintile 3 & $0.24(0.07-0.85)$ & $0.40(0.12-1.35)$ & $0.31(0.08-1.19)$ \\
\hline Quintile 4 & $0.25(0.07-0.94)$ & $0.29(0.07-1.10)$ & $0.13(0.03-0.65)$ \\
\hline Quintile 5 & $0.11(0.03-0.49)$ & $0.15(0.03-0.68)$ & $0.16(0.02-1.12)$ \\
\hline per unit increase in $\log (P C B)$ & $0.53(0.32-0.88)$ & $0.53(0.32-0.87)$ & $0.52(0.31-0.86)$ \\
\hline \multicolumn{4}{|c|}{ Excluding mothers whose GLSCF consumption changed a lot ( $\mathrm{n}=128$ mothers, 128 children) } \\
\hline Quintile I & 1.00 & 1.00 & 1.00 \\
\hline Quintile 2 & $0.21(0.05-0.91)$ & $0.36(0.09-1.48)$ & $0.5 \mathrm{I}(0.1 \mathrm{I}-2.27)$ \\
\hline Quintile 3 & $0.13(0.02-0.70)$ & $0.20(0.04-1.00)$ & $0.18(0.03-1.05)$ \\
\hline Quintile 4 & $0.14(0.02-0.89)$ & $0.17(0.03-1.10)$ & $0.05(<.01-0.47)$ \\
\hline Quintile 5 & $0.03(<.01-0.26)$ & $0.05(0.01-0.37)$ & $0.04(<.01-0.67)$ \\
\hline per unit increase in $\log (P C B)$ & $0.39(0.20-0.75)$ & $0.38(0.19-0.75)$ & $0.37(0.19-0.73)$ \\
\hline \multicolumn{4}{|c|}{ Model applied to GLSCF consumers only†, excluding mothers whose GLSCF consumption changed a lot ( $\mathrm{n}=128$ mothers, 128 children) } \\
\hline Quintile I & 1.00 & 1.00 & 1.00 \\
\hline Quintile 2 & $0.21(0.05-0.80)$ & $0.21(0.06-0.80)$ & $0.24(0.07-0.85)$ \\
\hline Quintile 3 & $0.34(0.09-1.32)$ & $0.27(0.07-1.04)$ & $0.43(0.12-1.53)$ \\
\hline Quintile 4 & $0.28(0.07-1.17)$ & $0.37(0.09-1.54)$ & $0.29(0.07-1.17)$ \\
\hline Quintile 5 & $0.13(0.03-0.62)$ & $0.14(0.03-0.65)$ & $0.28(0.06-1.4 I)$ \\
\hline per unit increase in $\log (P C B)$ & $0.56(0.34-0.93)$ & $0.61(0.39-0.97)$ & $0.74(0.53-1.05)$ \\
\hline
\end{tabular}

* Adjusted for the year of the child's birth, maternal and paternal age at the child's birth, the mother's parity at the child's birth, and whether the child had an older brother. † Serum PCB concentrations of non-GLSCF consumers were left unrevised.

polychlorinated dibenzofurans (PCDFs) as a result of heating the contaminated rice oil for cooking $[49,51,54]$. Whether these differences could explain the differences in sex ratio findings between the Yusho and Yu-cheng incidents and our findings is not clear.

A study of Great Lakes fish consumers in Michigan also found no relation between serum DDE concentrations and sex ratio, but did find that fathers with serum PCB concentrations greater than $8.1 \mathrm{ng} / \mathrm{mL}$ had a higher percentage of male children (OR for a male child: 2.29; 95\% CI: 1.11-4.74) than fathers with lower concentrations [31]. There was no evidence of a linear trend between PCB exposure and sex ratio in our data, although in some individual quintiles of $\mathrm{PCB}$ exposure, in some of our models, our results were in the same direction as the findings of the previous Michigan study [31], but generally not significant. The study of Michigan fish consumers did not find a significant relation between a dichotomous measure of maternal serum PCB concentration and sex ratio. Mothers with serum PCB concentration greater than $8.1 \mathrm{ng} / \mathrm{mL}$ had an odds ratio for a male child of 0.71 (95\% CI: 0.351.45) compared to mothers with lower serum PCB concentrations. The pattern of our current results over the quintiles of maternal serum PCB concentrations (fig. 3 and table 5), however, suggest that a dichotomization of the exposure could attenuate the odds ratio for a male child as a function of maternal exposure.

The sex ratio of live births could be affected as a result of post-conception effects of PCBs. It has been reported that maternal consumption of contaminated sport fish from Lake Ontario reduces menstrual cycle length and time to pregnancy [9-11]. The sex ratio of live births could be reduced if fecundity among women who consume contaminated GLSCF is reduced because of an increased rate of spontaneous abortion of male fetuses. Evidence may in fact suggest, although there is some debate, that exposure of female rhesus monkeys to aroclor 1254 (a mixture of PCB congeners) leads to a reduction in the sex ratio of offspring, possibly contributed to by increased spontaneous abortion of male fetuses [28-30]. Preconception parental estrogen levels have also been hypothesized to affect the sex ratio of live births [22], and given the estrogenic and anti-estrogenic actions of different PCB congeners $[57,58]$, this could be another mechanism by which parental exposure to PCBs alters the sex ratio.

An important limitation of our study is that the serum OC measurements were made several years after the birth con- 
Table 6: Odds ratios* $(95 \% \mathrm{Cl})$ for male child by paternal serum PCB quintile given different decay constants used to revise PCB concentrations.

\begin{tabular}{|c|c|c|c|}
\hline & \multicolumn{3}{|c|}{ Decay constant } \\
\hline & 0.06 & .08 & .15 \\
\hline \multicolumn{4}{|c|}{ Model applied to all fathers ( $n=108$ fathers, 208 children) } \\
\hline Quintile I & 1.00 & 1.00 & 1.00 \\
\hline Quintile 2 & $0.89(0.37-2.12)$ & $1.49(0.64-3.46)$ & $2.56(1.06-6.20)$ \\
\hline Quintile 3 & $1.30(0.6 \mathrm{I}-2.78)$ & $1.55(0.74-3.24)$ & $1.01(0.40-2.56)$ \\
\hline Quintile 4 & $1.30(0.55-3.08)$ & $1.32(0.55-3.19)$ & $1.02(0.40-2.68)$ \\
\hline Quintile 5 & $0.85(0.32-2.26)$ & $1.23(0.48-3.11)$ & $1.86(0.59-5.85)$ \\
\hline \multicolumn{4}{|c|}{ Excluding fathers whose GLSCF consumption changed a lot ( $\mathrm{n}=84$ fathers, 160 children) } \\
\hline Quintile I & 1.00 & 1.00 & 1.00 \\
\hline Quintile 2 & $0.81(0.30-2.18)$ & $1.31(0.5 \mid-3.37)$ & $2.07(0.83-5.12)$ \\
\hline Quintile 3 & $1.21(0.57-2.58)$ & $1.47(0.70-3.09)$ & $1.16(0.44-3.10)$ \\
\hline Quintile 4 & $1.06(0.40-2.83)$ & $1.14(0.4 \mid-3.2 I)$ & $1.04(0.36-3.06)$ \\
\hline Quintile 5 & $0.64(0.20-2.08)$ & $0.98(0.34-2.81)$ & $1.67(0.44-6.28)$ \\
\hline \multicolumn{4}{|c|}{ Model applied to GLSCF consumers onlyt, excluding fathers whose GLSCF consumption changed a lot ( $\mathrm{n}=84$ fathers, 160 children } \\
\hline Quintile I & 1.00 & 1.00 & 1.00 \\
\hline Quintile 2 & $1.59(0.83-3.05)$ & $1.50(0.77-2.91)$ & $1.54(0.78-3.05)$ \\
\hline Quintile 3 & $0.8 \mathrm{I}(0.4 \mathrm{I}-\mathrm{I} .6 \mathrm{I})$ & $0.92(0.46-1.87)$ & $1.09(0.49-2.43)$ \\
\hline Quintile 4 & $1.14(0.46-2.83)$ & $0.80(0.32-1.99)$ & $0.92(0.38-2.22)$ \\
\hline Quintile 5 & $0.78(0.28-2.18)$ & $0.95(0.35-2.53)$ & $0.94(0.3 \mathrm{I}-2.78)$ \\
\hline
\end{tabular}

* Adjusted for the year of the child's birth, maternal and paternal age at the child's birth, the mother's parity at the child's birth, and whether the child had an older brother. $†$ Serum PCB concentrations of non-GLSCF consumers were left unrevised.

sidered for analysis. We attempted to mitigate against this concern by running several analyses after revising the serum OC concentrations according to a toxicokinetic model to account for decreases in serum OC concentration during the interval between the birth and the blood draw. Our results for maternal exposure were quite robust to changes in the parameter of this model - as well as exclusion of those subjects who reported that their GLSCF consumption had changed a lot - although the results only hold insofar as the model of OC decline is accurate. It must also be considered that an association between higher maternal PCB levels and decreased odds of having a male child could be produced if delivering a male child were related to more rapid excretion of maternal PCBs in some way not related to factors controlled for in our regression models. An additional limitation is not having measurements of other possible contaminants. It is possible that some chemical, or combination of chemicals, other than PCBs in the fish could lead to the changes in sex ratio we found, although this may be less likely given the specificity of our results for serum PCB and not DDE. Lastly, it is possible that these results could be confounded by fish consumption itself if fish consumption affects the sex ratio, although we are not aware of any evidence to this effect.

\section{Conclusions}

Our data suggest that maternal exposure to PCBs may decrease the sex ratio of offspring. While there is some suggestion that paternal exposure to PCBs may increase the sex ratio, this finding was not robust. Nonetheless, caution may be warranted in interpreting null findings of the effect of chemicals on the sex ratio as indicating no effect because of the possibility of opposing effects of maternal and paternal exposure. Although the overall decline in sex ratio over the past few decades may not be attributable to general environmental contamination, these results add to the growing body of evidence that exposure to particular chemicals can alter the sex ratio.

\section{Competing interests}

None of the authors have received reimbursements, fees, funding, or salary from an organization that may in any way gain or lose financially from the publication of this paper in the past five years.

None of the authors have held any stocks or shares in an organization that may in any way gain or lose financially from the publication of this paper.

None of the authors have any other financial competing interests. 
There are no non-financial competing interests to declare in relation to this paper.

\section{Authors' contributions}

HA, and LH participated in the design and coordination of the study. MW performed the statistical analysis with input from LH. MW wrote the manuscript. All authors read and approved the final manuscript.

\section{Additional material}

\section{Additional file 1}

Appendix

Click here for file

[http://www.biomedcentral.com/content/supplementary/1476069X-2-2-S1.doc]

\section{Acknowledgements}

This work was supported by funding from the Agency for Toxic Substances and Disease Registry.

\section{References}

I. United States Environmental Protection Agency Proceedings of the U.S. Environmental Protection Agency's national technical workshop "PCBs in fish tissue". EPA\# 823-R-93-003. Washington, DC 1993,

2. Cordle F, Locke R and Springer J Risk assessment in a federal regulatory agency: an assessment of risk associated with the human consumption of some species of fish contaminated with polychlorinated biphenyls (PCBs). Environ Health Perspect 1982, 45: $17 \mid-82$

3. Newsome $\mathrm{WH}$ and Andrews P Organochlorine pesticides and polychlorinated biphenyl congeners in commercial fish from the Great Lakes. J AOAC Int 1993, 76:707-10

4. Longnecker MP, Rogan WJ and Lucier G The human health effects of DDT (dichlorodiphenyltrichloroethane) and PCBS (polychlorinated biphenyls) and an overview of organochlorines in public health. Annu Rev Public Health 1997, I 8:2 I I-44

5. Anderson HA, Hanrahan LP, Falk C, Tilden J, Olson J and and the Great Lakes Consortium Sport fish consumption: an important route of exposure to persistent chemical pollutants. Eur J Oncol 1998, 3:32I-327

6. Fiore BJ, Anderson HA, Hanrahan LP, Olson LJ and Sonzogni WC Sport fish consumption and body burden levels of chlorinated hydrocarbons: a study of Wisconsin anglers. Arch Environ Health 1989, 44:82-8

7. Hovinga ME, Sowers $M$ and Humphrey HE Environmental exposure and lifestyle predictors of lead, cadmium, РСВ, and DDT levels in Great Lakes fish eaters. Arch Environ Health 1993 , 48:98-104

8. Hanrahan LP, Falk C, Anderson HA, Draheim L, Kanarek MS and OIson J Serum PCB and DDE levels of frequent Great Lakes sport fish consumers-a first look. The Great Lakes Consortium. Environ Res 1999, 80:S26-S37

9. Mendola P, Buck GM, Sever LE, Zielezny M and Vena JE Consumption of PCB-contaminated freshwater fish and shortened menstrual cycle length. Am J Epidemiol 1997, 146:955-60

10. Buck GM, Sever LE, Mendola P, Zielezny M and Vena JE Consumption of contaminated sport fish from Lake Ontario and timeto-pregnancy. New York State Angler Cohort. Am J Epidemiol 1997, 146:949-54

II. Buck GM, Vena JE, Schisterman EF, Dmochowski J, Mendola P, Sever LE, Fitzgerald E, Kostyniak P, Greizerstein $\mathrm{H}$ and Olson J Parental consumption of contaminated sport fish from Lake Ontario and predicted fecundability. Epidemiology 2000, I I:388-93
12. Fein GG, Jacobson JL, Jacobson SW, Schwartz PM and Dowler JK Prenatal exposure to polychlorinated biphenyls: effects on birth size and gestational age. J Pediatr 1984, 105:315-20

13. Faroon $O$, Jones $D$ and de Rosa $C$ Effects of polychlorinated biphenyls on the nervous system. Toxicol Ind Health 200I, 16:30533

14. Jacobson SW, Fein GG, Jacobson JL, Schwartz PM and Dowler JK The effect of intrauterine PCB exposure on visual recognition memory. Child Dev 1985, 56:853-60

15. Jacobson JL, Jacobson SW and Humphrey HE Effects of in utero exposure to polychlorinated biphenyls and related contaminants on cognitive functioning in young children. J Pediatr 1990, I 16:38-45

16. Jongbloet PH, Zielhuis GA, Groenewoud HM and Pasker-De Jong PC The secular trends in male:female ratio at birth in postwar industrialized countries. Environ Health Perspect 200I, 109:749-52

17. Davis DL, Gottlieb MB and Stampnitzky JR Reduced ratio of male to female births in several industrial countries: a sentinel health indicator? J Am Med Assoc 1998, 279:1018-23

18. Vartiainen $T$, Kartovaara $L$ and Tuomisto J Environmental chemicals and changes in sex ratio: analysis over 250 years in finland. Environ Health Perspect 1999, 107:8I3-5

19. James WH Re: the use of offspring sex ratios in the search for endocrine disruptors. Environ Health Perspect 1998, 106:A472-3

20. James WH Was the widespread decline in sex ratios at birth caused by reproductive hazards? Hum Reprod 1998, I3:1083-4

21. James $\mathrm{WH}$ Sex ratios at birth as monitors of endocrine disruption. Environ Health Perspect 200 I, 109:A250-I

22. James WH Evidence that mammalian sex ratios at birth are partially controlled by parental hormone levels at the time of conception. J Theor Biol 1996, 180:27I-86

23. Goldsmith JR, Potashnik $G$ and Israeli $R$ Reproductive outcomes in families of DBCP-exposed men. Arch Environ Health 1984, 39:85-9

24. Potashnik G and Yanai-Inbar I Dibromochloropropane (DBCP): an 8-year reevaluation of testicular function and reproductive performance. Fertil Steril 1987, 47:317-23

25. Safe SH Endocrine disruptors and human health - is there a problem? An update. Environ Health Perspect 2000, 108:487-93

26. Mocarelli P, Brambilla P, Gerthoux PM, Patterson DG Jr and Needham LL Change in sex ratio with exposure to dioxin. Lancet 1996, 348:409

27. Mocarelli P, Gerthoux PM, Ferrari E, Patterson DG Jr, Kieszak SM, Brambilla P, Vincoli N, Signorini S, Tramacere P, Carreri V, Sampson EJ, Turner WE and Needham LL Paternal concentrations of dioxin and sex ratio of offspring. Lancet 2000, 355:1858-63

28. Arnold DL, Bryce F, McGuire PF, Stapley R, Tanner JR, Wrenshall E, Mes J, Fernie S, Tryphonas $\mathrm{H}$ and Hayward S Toxicological consequences of aroclor I 254 ingestion by female rhesus (Macaca mulatta) monkeys. Part 2. Reproduction and infant findings. Food Chem Toxicol 1995, 33:457-74

29. James $\mathrm{WH}$ The sex ratio of offspring of female rhesus monkeys exposed to Aroclor 1 254. Food Chem Toxicol 1998, 36:45 I-3

30. James WH Rejoinder to the letter of Drs Arnold and Hayward. Food Chem Toxicol 1998, 36:54I

31. Karmaus W, Huang $S$ and Cameron L Parental concentration of dichlorodiphenyl dichloroethene and polychlorinated biphenyls in Michigan fish eaters and sex ratio in offspring. J Occup Environ Med 2002, 44:8-13

32. del Rio Gomez I, Marshall T, Tsai P, Shao YS and Guo YL Number of boys born to men exposed to polychlorinated byphenyls. Lancet 2002, 360:143-4

33. Travers $M$, Buck $G$ and Vena J Paternal fish consumption and secondary sex ratio [Abstract]. Epidemiology 2000, I I:S6I

34. Yoshimura $T$, Kaneko $S$ and Hayabuchi $H$ Sex ratio in offspring of those affected by dioxin and dioxin-like compounds: the Yusho, Seveso, and Yucheng incidents. Occup Environ Med 200I, 58:540-I

35. Rogan WJ, Gladen BC, Guo YL and Hsu CC Sex ratio after exposure to dioxin-like chemicals in Taiwan. Lancet 1999, 353:206-7

36. Anderson H, Falk C, Fiore B, Hanrahan L, Humphrey HE, Kanarek M, Long T, Mortensen K, Shelley T, Sonzogni B, Steele G and Tilden J Consortium for the Health Assessment of Great Lakes Sport Fish Consumption. Toxicol Ind Health 1996, I 2:369-73

37. Burse VW, Groce DF, Korver MP, McClure PC, Head SL, Needham LL, Lapeza CR Jr and Smrek AL Use of reference pools to com- 
pare the qualitative and quantitative determination of polychlorinated biphenyls by packed and capillary gas chromatography with electron capture detection. Part I. Serum. Analyst 1990, I 1 5:243-5 I

38. Wisconsin Laboratory of Hygiene Methods manual. Organic chemistry (Edited by: Madison WI) University of Wisconsin 1987,

39. Needham LL and Wang RY Analytic considerations for measuring environmental chemicals in breast milk. Environ Health Perspect 2002, I I0:A317-24

40. Hornung RW and Reed LD Estimation of average concentration in the presence of nondetectable values. Appl Occup Environ Hyg |990, 5:46-5|

4I. Griffith WC, Curl CL, Fenske RA and Raustman EM Statistical methods for evaluating samples below detection limits [Abstract]. Epidemiology 2002, 13:S256

42. Hanrahan LP, Anderson HA, Falk C, Olson J and and the Great Lakes Consortium Reproductive predictors of serum PCB and DDE levels among frequent Great Lakes sport fish consumers: the role of gender, births and breastfeeding. Eur J Oncol 1999, 4:585-593

43. Dobie SA, Baldwin LM, Rosenblatt RA, Fordyce MA, Andrilla $\mathrm{CH}$ and Hart LG How well do birth certificates describe the pregnancies they report? The Washington State experience with low-risk pregnancies. Matern Child Health J 1998, 2: I45-54

44. Piper JM, Mitchel EF Jr, Snowden M, Hall C, Adams M and Taylor P Validation of 1989 Tennessee birth certificates using maternal and newborn hospital records. Am J Epidemiol 1993, I37:75868

45. SAS Institute Inc. SAS/STAT User's Guide, Version 8 (Edited by: Cary NC) SAS Institute Inc. 1999,

46. James WH Offspring sex ratios of people exposed to dioxin and dioxin-like compounds. Occup Environ Med 2002, 59:202discussion 202

47. James $\mathrm{WH}$ The human sex ratio. Part I: A review of the literature. Hum Biol 1987, 59:721-52

48. Michalek JE, Rahe AJ and Boyle CA Paternal dioxin and the sex of children fathered by veterans of Operation Ranch Hand. Epidemiology 1998, 9:474-5

49. Chen PH, Wong CK, Rappe C and Nygren M Polychlorinated biphenyls, dibenzofurans and quaterphenyls in toxic rice-bran oil and in the blood and tissues of patients with $\mathrm{PCB}$ poisoning (Yu-Cheng) in Taiwan. Environ Health Perspect 1985, 59:59-65

50. Hsu ST, Ma Cl, Hsu SK, Wu SS, Hsu NH, Yeh CC and Wu SB Discovery and epidemiology of $P C B$ poisoning in Taiwan: a fouryear followup. Environ Health Perspect 1985, 59:5-10

5I. Masuda Y, Kuroki H, Haraguchi K and Nagayama J PCB and PCDF congeners in the blood and tissues of yusho and yu-cheng patients. Environ Health Perspect 1985, 59:53-8

52. Rogan WJ, Gladen BC, Hung KL, Koong SL, Shih LY, Taylor JS, Wu YC, Yang D, Ragan NB and Hsu CC Congenital poisoning by polychlorinated biphenyls and their contaminants in Taiwan. Science 1988, 241:334-6

53. Yen YY, Lan SJ, Ko YC and Chen C] Follow-up study of reproductive hazards of multiparous women consuming PCBs-contaminated rice oil in Taiwan. Bull Environ Contam Toxicol 1989, 43:647-655

54. Kashimoto T, Miyata H, Fukushima S, Kunita N, Ohi G and Tung TC PCBs, PCQs and PCDFs in blood of yusho and yu-cheng patients. Environ Health Perspect 1985, 59:73-8

55. Sonzogni W, Maack L, Gibson T, Degenhardt D, Anderson H and Fiore $B$ Polychlorinated biphenyl congeners in blood of Wisconsin sport fish consumers. Arch Environ Contam Toxicol I99I, 20:56-60

56. Newsome WH, Andrews P, Conacher HB, Rao RR and Chatt A Total organochlorine content of fish from the Great Lakes. J AOAC Int 1993, 76:703-6

57. Jansen HT, Cooke PS, Porcelli J, Liu TC and Hansen LG Estrogenic and antiestrogenic actions of PCBs in the female rat: in vitro and in vivo studies. Reprod Toxicol 1993, 7:237-48

58. McKinney JD and Waller CL Polychlorinated biphenyls as hormonally active structural analogues. Environ Health Perspect 1994, 102:290-7
Publish with Biomed Central and every scientist can read your work free of charge

"BioMed Central will be the most significant development for disseminating the results of biomedical research in our lifetime. "

Sir Paul Nurse, Cancer Research UK

Your research papers will be:

- available free of charge to the entire biomedical community

- peer reviewed and published immediately upon acceptance

- cited in PubMed and archived on PubMed Central

- yours - you keep the copyright

Submit your manuscript here:

http://www.biomedcentral.com/info/publishing_adv.asp
BiolMedcentral 